\title{
UNA NUEVA APROXIMACIÓN AL NEOGÓTICO GADITANO: EL PROYECTO DE SAGRARIO Y DEPENDENCIAS CAPITULARES DE LA CATEDRAL NUEVA GADITANA
}

\author{
A NEW APPROACH TO NEOGOTICO \\ GADITANO: SAGRARIO PROJECT AND UNITS \\ CAPITULANTS NEW CATHEDRAL GADITANA
}

\author{
JuAn Ramón Cirici NARváez \\ Universidad de Cádiz, España \\ ramon.cirici@uca.es
}

Dentro de la arquitectura neogótica que germina en las ciudades españolas del último tercio del siglo XIX, y entre otras obras de carácter aplicado y religioso, encontramos el proyecto que para Capilla del Sagrario y dependencias capitulares de la Catedral Nueva de Cádiz diseña el arquitecto diocesano Juan de la Vega. La incorporación del nuevo estilo a un establecimiento de concepción barroca y culminación neoclásica levantará el recelo y la duda de los promotores, la consulta académica y, a la postre, el rechazo del propósito.

Palabras claves: Neogótico, Capilla del Sagrario y dependencias capitulares, Catedral Nueva de Cádiz, Academia, indefinición estilística.

Within the neo-Gothic architecture that germinates in the Spanish cities of the last third of the nineteenth century, and among other works of applied and religious character, found the project to Capilla del Sagrario and Chapter offices of the New Cathedral of Cadiz architect designs diocesan Juan de la Vega. The incorporation of the new style to a setting Baroque and neoclassical conception culmination raise suspicion and doubt developers, academic consultation and, ultimately, rejection of purpose.

Keywords: Gothic Revival, Capilla del Sagrario and chapter dependencies, New Cathedral of Cadiz, Schools, stylistic definition.

Valgan mis primeras palabras para mostrar mi alegría y agradecimiento por participar en esta efeméride de pleno merecimiento. He tenido la suerte de 
conocer y gozar del trato y apoyo del Prof. Teodoro Falcón Márquez, a quien admiro por su labor pero, sobre todo, por su carácter y perseverancia, su humildad y capacidad de transmitir siempre seguridad y ganas de trabajar, de seguir.

\section{EL NEOGÓTICO${ }^{1}$ EN LA CIUDAD DE CÁDIZ. ANTECEDENTES Y CONSECUENTES.}

Quizás los antecedentes más primigenios del neogótico en la ciudad, y en contra de lo que se pudiera pensar, vienen dados por la arquitectura civil, doméstica, más concretamente, y en detalles menores que, en su momento, pudieran pasar desapercibidos para la propia ciudadanía. Cronológicamente el primero pertenece aún a la primera mitad del siglo XIX, 1849, y es una pequeña torre mirador. Prohibida la erección de las mismas por las Ordenanzas Municipales de la ciudad de Cádiz de 1792 al considerarse "parte inútil de los edificios, destinada al entretenimiento y la curiosidad y no a la comodidad y uso de las casas"2 unas nuevas de 1845 permitían nuevamente su fábrica a partir de materiales livianos, no de obra, madera, hierro y cristal ${ }^{3}$. La idea se corresponde con el pensamiento del arquitecto Juan de la Vega ${ }^{4}$ y viene fechada en diciembre de $1849^{5}$, apenas cuatro años después de su provisión. Aprobados los planos por el maestro de obras Pascual Olivares, quien actuaba como Arquitecto Mayor de Ciudad interino, se puede observar en el proyecto la planta y alzado aunque no así la estructura interior y el corte de las maderas como preveía las Ordenanzas. Ejemplar original y escaso en su género presenta tres cuerpos, los dos primeros formando sendos cubos cuadrados, con estructura interior de viguería de madera y exterior de mampostería, y un tercero octogonal, abierto y acristalado en todos sus lados con detalles a manera de celosías góticas. La cubierta se cierra con un tejado a ocho aguas y se remata con un airoso y esbelto pináculo. Ecléctico e historicista preludio de lo que se avecinaba. Su destino una finca de la calle del Tinte de la que no se especifica el número ni propietario. En cualquier caso su ubicación, siguiendo, asimismo, la nueva normativa, no le permitía ser vista desde la calle.

\footnotetext{
${ }^{1}$ Para un mejor entendimiento del estilo neogótico léase a AZCÁRATE Y RISTORI, José $\mathrm{M}^{\mathrm{a}}$, en Neogoticismo del siglo XIX en Madrid, Madrid, 1981.

${ }^{2}$ Aunque la realidad no era otra que la pérdida de su originaria función en el tráfico comercial tras la pérdida de las colonias americanas.

${ }^{3}$ CIRICI NARVAEZ, Juan R.: "Las torres-miradores gaditanas durante el siglo XIX”, Laboratorio del Arte, 22, 2010, pp. 317-338.

${ }^{4}$ CIRICI NARVAEZ, Juan R.: Juan de la Vega y la arquitectura gaditana del Siglo XIX, Cádiz, 1995, pp. 109-188.

${ }^{5}$ AHMC. SP. (Archivo Histórico Municipal de Cádiz. Sección de planos), libro 15, 19 de diciembre de 1849.
} 
La siguiente referencia la encontramos en la finca de la plaza de San Antonio $\mathrm{n}^{\circ}$ 6, esquina a Cánovas del Castillo, actual sede del Instituto de la Seguridad Social ${ }^{6}$. Su autor el maestro de obras Diego Filguera, natural y vecino de Cádiz, 1795, fallecido en El Puerto de Santa María en 1862. Examinado maestro de obras en diciembre de 1833 por la Academia de San Fernando de Madrid7, centrará su actividad profesional entre la capital y El Puerto de Santa María proyectando edificios de auténtico interés abandonando la repetición neoclásica y ensayando nuevos ejercicios tanto en los materiales, herrajes, principalmente, como en los elementos decorativos de inspiración historicista. Las fincas números 54 y 55 -antiguos- de la calle de San Francisco ${ }^{8}$ y la número 135 -antiguo- de la plaza Isabel $\mathrm{II}^{9}$, actual de San Juan de Dios, se mantienen aún próximas a los esquemas tradicionales clásicos no ofreciendo especial singularidad. Sin embargo la número 141 -antiguo- de la calle Ancha ${ }^{10}$ rompe las proporciones en favor de la altura, con planta baja y tres pisos y tres hileras de vanos. Los juegos de los herrajes de los balcones, formando aros entrelazados, y la alternancia del almohadillado dan un nuevo ritmo y gracia a la fachada.

Finalmente, y volviendo a la plaza de San Antonio $n^{\circ}$ 6, Filguera levanta en 1857 para el Conde de Casa Brunet un edificio de una monumentalidad sorprendente, ofreciendo una doble fachada, a la plaza y a la calle lateral, destacando la primera con planta baja, entresuelo, principal y piso alto, y cinco hileras de vanos ordenados mediante pilastras, almohadilladas unas, pareadas y cajeadas otras. El apretilado de la azotea se remata por una serie de jarrones de piedra. El pronunciado arco apuntado de la puerta principal de acceso nos deja entrever un incipiente, acaso exótico, romanticismo goticista.

No muy lejos de allí, en la misma plaza de San Antonio, encontramos otro importante testimonio. En este caso aplicado ya a la arquitectura religiosa. En 1866 el arquitecto Fernando Ortiz Vierna ${ }^{11}$ recibe el encargo de construir dos capillas para la Iglesia Parroquial de San Antonio. Nacido en Meruelo, provincia de Santander, en 1827, culminará sus estudios en la Escuela de Arquitectura madrileña en $1852^{12}$. En 1855 aparece residiendo en Cádiz, solicitando licencia para el

${ }^{6}$ AHMC. SP., libro 17, 31 de agosto de 1857.

${ }^{7}$ AABASFM (Archivo Academia de Bellas Artes de San Fernando de Madrid), Registro de Maestros de Obras aprobados por esta Real Academia..., número 105, libro 3/156, folio 13 vto.

${ }^{8}$ AHMC. SP., libro 15, 30 de octubre de 1849.

${ }^{9}$ Ibidem, libro 16,1850 .

${ }^{10}$ Ibid. , 1853.

${ }^{11}$ CIRICI NARVAEZ, Juan R.: Juan de la Vega y la arquitectura..., op. cit., pp. 72-76.

12 AABASFM, Escuela Especial de Arquitectura, año 1849, libro 3/152, p. 282.

${ }^{12}$ AABAC. (Archivo Academia de Bellas Artes de Cádiz), Títulos administrativos de Ortiz Vierna, Libro Registro de Títulos, 1852-1.864. 
libre ejercicio de la profesión a la vez que ingresa como profesor en la Academia de Bellas Artes gaditana en las enseñanzas de maestros de obras, agrimensores y aparejadores $^{13}$. Igualmente ejercerá la plaza de Arquitecto Mayor de Ciudad ${ }^{14}$ y de Conservador del recién creado Museo de Bellas Artes de la provincia de Cádiz.

En la finca ${ }^{\circ} 13$ de la calle Hércules, realizada en 1858 , de dos plantas y marcada horizontalidad, Ortiz nos presenta en su doble fachada una composición e inclusión de elementos decorativos, molduras y herrajes, novedosos para la fecha ${ }^{15}$. Sugestión que acrecienta en el "Proyecto de la Casa que D. Agustín Blázquez trata de construir en la calle de la Novena con vuelta a las del Vestuario y Comedias", junio de $1861^{16}$, y que constituye una de las fincas más extraordinarias del siglo XIX gaditano. La fachada principal, a la calle Novena, presenta planta baja y dos pisos, siguiendo la inclinación de la calle, y nueve hileras de vanos, tres en el cuerpo central, donde se encuentra la puerta de acceso, y otras tres a cada lado. Su proyección en las calles Vestuario y Comedias modifica los ángulos en amables trazados curvos dando lugar en los distintos pisos a llamativos balcones cerrados por cristaleras y abarquillado recorrido. El auxilio de los elementos complementarios y decorativos, ménsulas, florales cornisas y guardapolvos, estilizados herrajes y sinuosos vitrales, al par que elegancia nos sitúa ante un eclecticismo novedoso y complejo que nos recuerda las construcciones domésticas de la Inglaterra Victoriana.

La Iglesia de San Antonio había sufrido recientemente importantes obras tanto en su interior, altar mayor, como en el exterior, incorporándosele una nueva torre y procediéndose a la actualización de cubiertas y fachadas ${ }^{17}$. Y en este proceso de ampliación y mejoras del templo se proyectan, y llevan a cabo, las Capillas del Sagrario y la de Ntro. Padre Jesús Nazareno. Los planos y diseños son aprobados por la Academia con fecha de 7 de julio de 1866 dándose paso a las obras inmediatamente ${ }^{18}$.

En la primera se crea un espacio ochavado bajo cúpula sobre pechinas con tambor y media naranja. Suelos y paramentos quedan recubiertos por mármoles y jaspes de distintas tonalidades, predominando los grises. Series de pilastras con grutescos compartimentan los tramos y ordenan cuatro hornacinas con las esculturas de los Cuatro Evangelistas. En la parte superior medallones en alto relieve

${ }^{13}$ AABAC. (Archivo Academia de Bellas Artes de Cádiz), Títulos administrativos de Ortiz Vierna, Libro Registro de Títulos, 1852-1.864.

${ }_{14}$ AHMC.AC. (Actas Capitulares), Cabildo 5 de julio 1857.

15 AHMC. SP., libro 17, Marzo 1858.

${ }_{16}$ AHMC. SP., libro 18, Junio 1861.

${ }^{17}$ AABAC. O.D. (Oficios y Documentos), año 1858. Informe elaborado por el arquitecto académico Juan de la Vega y Correa en el que si bien se cita el proyecto no se hace mención de su autor, extendiéndose en consideraciones y correcciones.

${ }^{18}$ Ibídem, año 1866. 
motivan las estaciones del Vía Crucis. Frente al arco de ingreso, y cerrado por una vistosa reja, se sitúa el altar y, en él, el Sagrario de estilo gótico. Éste, a manera de tabernáculo, presenta planta, igualmente, ochavada bajo cúpula de media naranja y lados abiertos con arcos de medio punto y gabletes en, lo que podemos llamar, armónica disonancia con la arquitectura de la capilla cuya evocación renacentista nos traslada a las iglesias florentinas del cuattrocento. Sin duda, toda una genial síntesis eclecticista.

La capilla del Nazareno se ejecuta algo después, en 1871. En el lateral izquierdo de la fachada principal se incorpora una construcción cuadrangular en torno a un patio central, a manera de claustro, con arcos sobre pilares de mármol ochavados. El exterior, con fachada a la plaza de San Antonio y a la calle Zaragoza, donde se sitúa la puerta de acceso al añadido, se articula mediante pilastras que arrancan de un alto zócalo y series de vanos con cristaleras de inspiración gótica. Esta nueva actuación, que afectará por extensión a las torres y conjunto, opera en el edificio una acumulación de estilos arquitectónicos. Sobre la base del pórtico barroco, correspondiente a la segunda mitad del XVII, la reforma de 1858 añade la torre izquierda, a juego con la ya existente, cuyos cubos de arranque como disposición general de la fachada, frontón triangular y otros detalles, son de adscripción tardoneoclásica. Por último Ortiz Vierna introduce el estilo neogótico propio del último tercio del siglo XIX. Las torres quedan rematadas por llamativos y estilizados chapiteles de estructura de madera y exterior de pizarra y zinc con remates de pináculos apuntados. Los vanos de las fachadas, a juego con los del añadido, se convierten en rosetones y ventanales de polícromas vidrieras y pretendidas celosías medievales. Nuevamente el arquitecto se nos muestra libre de ataduras, innovador y ecléctico, de acuerdo con el uso revisionista de los estilos históricos.

Como consecuentes al proyecto catedralicio, 1872, y más ajustados a la cronología y desarrollo del estilo encontramos, nuevamente, numerosas e importantes intervenciones correspondientes a otros tantos arquitectos. Cayetano Santola$1 \mathrm{a}^{19}$, natural de Ajamil, provincia de Logroño, 1837, estudia en la Academia de Bellas Artes gaditana donde cursa los estudios de maestro de obras, agrimensor y de director de caminos vecinales. Bagaje con el que marcha a Madrid ingresando en la Escuela Especial de Arquitectura siendo aprobado con fecha de noviembre de $1866^{20}$. Profesor de la Escuela de Bellas Artes gaditana ${ }^{21}$ accederá en 1873 a la plaza de Arquitecto Mayor de Ciudad, en la que permanecerá hasta 1900.

De una actividad tan rica como variada, proyectará un segundo mercado ${ }^{22}$ para la ciudad, 1871, en la plaza de la Merced; intervendrá en la adaptación del

\footnotetext{
${ }^{19}$ CIRICI NARVAEZ, Juan R.: Juan de la Vega y la arquitectura ..., op.cit., pp. 80-2.

${ }^{20}$ AABASFM, Libro Registro Maestros Arquitectos..., número 124, 3/154, fol. 84.

${ }^{21}$ AABAC, Libro Copiador de Certificaciones, 1850-1868, núm. 194.

${ }^{22}$ AHMC. SP., cajón 1, 11 de noviembre de 1871.
} 
Convento de San Agustín a Instituto de Segunda Enseñanza ${ }^{23}$; construirá un Asilo de Párvulos y Escuelas Públicas ${ }^{24}$ en la calle Corralón de los Carros, 1876, que, acabado, se destinará a sede de las recién creadas Audiencias Provinciales; levantará el Asilo de San José, 1883, en el barrio del Balón; y siendo el encargado de la inspección de las obras del nuevo Gran Teatro, iniciadas en 1884, elaborará un proyecto de ejecución del mismo ${ }^{25}, 1897$, que no llegará a llevarse a cabo.

$\mathrm{Su}$ aportación goticista, y no solo por las formas sino por lo que guarda de espiritualidad, viene dada por los numerosos mausoleos que para el Cementerio Católico de la ciudad fueron diseñados y ejecutados por su mano. Así, y entre otros, tres de singular relevancia: el encargado por la familia Uruela y González de Peredo para su hija pequeña "María”26, 1880; el de Pedro Pascual de Vela, firmados los planos en $1886^{27}$; y el del alcalde Eduardo J. Genovés, cuyo proyecto, de $1892^{28}$, remata en superficie la losa con un airoso templete gótico a manera de tabernáculo, de mármol y evocaciones trecentistas. De planta cuadrada bajo cúpula elíptica rematada por floridos pináculos incorpora todo el repertorio de elementos goticista en pilares, arcos y paramentos.

Un nuevo testimonio se corresponde con una construcción del arquitecto Amadeo Rodríguez y Rodríguez ${ }^{29}$. Nacido en Salamanca en 1840 es aprobado arquitecto por la Escuela Especial de Arquitectura de Madrid en enero de $1866^{30}$. Arquitecto Provincial, su estancia y actividad en Cádiz hay que centrarla en la década de los años ochenta y parte de los noventa desarrollando, igualmente, su profesión en otros lugares. A destacar, y con anterioridad, sus trabajos en la ciudad de Córdoba, Plaza de Toros de los Tejares, reconstruida tras un incendio en 1863 e inaugurada tres años después, incorporando pilares de fundición; el Gran Teatro, cuyas obras comenzaron en 1871 acabándose en 1873, con sala en forma de herradura, siguiendo los modelos de teatro italianos; reconstrucción de la ermita del Cristo del Pretorio, mismo año de 1873; y, a partir de 1882, junto con el arquitecto Rafael de Luque, las Casas Consistoriales. Igualmente es autor del proyecto y ejecución del Ayuntamiento algecireño ${ }^{31}$. Ya en Cádiz, lleva a cabo la reforma de las fincas n 20 y 21 de la calle de la Aduana, hoy Ramón de Carranza, 1890, para los Marqueses de Angulo dando lugar a una insólita construcción, de gran espectacularidad

\footnotetext{
${ }^{23}$ Ibídem, cajón 3, núm. 35.

${ }^{24}$ Ibíd., Proyecto de Asilo de Párvulos y Escuelas Públicas, 1876.

${ }^{25}$ MORENO CRIADO, Ricardo: Gran Teatro Falla, Cádiz, 1985, p. 17.

${ }^{26}$ AABAC. OD., año 1880.

${ }^{27}$ AHMC. SP., cajón 11, $\mathrm{n}^{\circ}$ 71, 1886.

${ }^{28}$ Ibídem, cajón $1, \mathrm{n}^{\circ}$ 22, 1892.

${ }^{29}$ CIRICI NARVAEZ, Juan R.: Juan de la Vega y la arquitectura..., op. cit., pp. 82-84.

${ }^{30}$ AABASF, Libro Registro Maestros Arquitectos..., número 117, 3/154, folio 80.

${ }^{31}$ ARANDA BERNAL, Ana Ma . y QUILES, Fernando: "Amadeo Rodríguez y su proyecto para el Ayuntamiento de Algeciras", Almoraima n 10, 1993, pp. 35-43.
} 
y eclecticismo estilístico, próxima al Modernismo ${ }^{32}$. Destacables, igualmente, son la reconstrucción del Colegio de San Felipe, prácticamente en ruinas, 1891, las Escuelas de los Hermanos de la Salle, en el Campo del Sur, para la Fundación Moreno de Mora, conocidas, vulgarmente, como la Mirandilla, así como su labor en la Exposición Marítima del año 1887, cuyos pabellones ofrecían como reclamo llamativos y exóticos exteriores, destacando los islamismos y las aportaciones orientales así como la inmediatez del Modernismo. En esta línea novedosa hay que considerar a Rodríguez, identificado con las corrientes historicistas de la época manifestando tanto inclinaciones goticistas y medievales, en general, como renacentistas y neoclásicas.

En 1889 Amadeo Rodríguez trabaja en el Oratorio de las Madres Reparadoras de la calle Zaragoza de Cádiz. Si bien en el interior de la capilla no se observa especial particularidad estilística el exterior se adorna con molduras mixtilíneas y apuntamientos. El plano original ${ }^{33}$ nos lleva a un novedoso y audaz alzado con una puerta de acceso descentrada, bajo conopio y jambas con bolas, rosetón enmarcado en sendas molduras y llamativo apretilado con crestería y flanqueado por dos grandes pináculos poligonales de piedra a manera de torres culminados en una cruz. La realidad fue más modesta y solo se ejecuta algunos detalles y molduras, a destacar la cornisa con bolas, de su primitivo espíritu medieval.

Del arquitecto Bartolomé Romero Fernández es la construcción de la casa $\mathrm{n}^{\mathrm{o}} 26$ de la calle de San Francisco y que, por su monumentalidad, se revela como uno de los ejemplos de arquitectura neogótica más importante de la ciudad. Llegadas a la ciudad las Esclavas del Sagrado Corazón de Jesús en 1890 se establecieron, primeramente, en la conocida Casa de las Columnas, calle Cristóbal Colón $n^{\circ} 12$, actual Archivo Histórico Provincial. Tras un peregrinaje de cuatro años por distintos establecimientos la Congregación adquirirá el edificio del Consulado, encargando al arquitecto Cayetano Santolalla la ampliación y reforma del mismo. Conservados los planos en el Archivo Histórico Municipal de Cádiz, marzo de $1896^{34}$, a su remodelación incorporará un nuevo piso. Pasados apenas cuatro años, filtraciones de agua y problemas en su estructura llevará a una reconstrucción integral del edificio encargándose de la misma Bartolomé Romero Fernández. Firmados por éste los planos el 31 de mayo de $1900^{35}$ en el expediente que acompaña se solicita una mayor altura a la regulada. Tras el cambio en la dirección de las obras por Mariano González Rojas, 1903, en noviembre de 1905 se comunica el fin de las obras haciéndose inclusión de la reconstrucción de la contigua casa $n^{\circ} 28$ para residencia de la Congregación.

\footnotetext{
${ }^{32}$ AHMC. SP., cajón 3, n 220, 1890.

${ }^{33}$ AHMC. SP., 2 de diciembre de 1889.

${ }^{34}$ AHMC. SP., marzo de 1896.

${ }^{35}$ AHMC. SP., 31 de mayo de 1900.
} 
Acomodado perfectamente el edificio a las características del solar, un trapecio irregular, como puede verse en el plano que acompaña al proyecto, sus recias y esbeltas fachadas alternan la eficacia del ladrillo rojo visto con los huecos donde se juega en el trazado de los mismos y la variedad de molduras y remates de ascendencia gótica. Una vez abandonada su primitiva función será reformado, fue sede de la Caja de Ahorros de Cádiz y actual de UNICAJA, adaptándose, 2009, íntegramente a uso cultural ${ }^{36}$.

Y terminamos este recorrido por el neogótico gaditano con otra singular construcción, la Capilla del Beato Diego José de Cádiz. Su autor el arquitecto Juan Cabrera Latorre ${ }^{37}$, natural de Sevilla, 1869. Entre 1886 y 1893 estudia en la Escuela Especial de Arquitectura madrileña llegando a Cádiz en el año 1903 ocupando la plaza de Arquitecto Mayor de la Ciudad. Con anterioridad ejerció ese mismo puesto en Haro, Logroño, donde dejó también una importante labor. Pese a su corta estancia, debido a lo prematuro de su fallecimiento, Cabrera llevará a buen término una de las construcciones más interesantes de la transición del siglo XIX al XX y de mayor significación para la ciudad: el Gran Teatro de Cádiz, hoy Falla, culminando los trabajos de fábrica en 1905 e inaugurándose en enero de $1910^{38}$. Ecléctico en todas sus manifestaciones dejará claves de su obra en edificios como la finca número 1 de la plaza de la Constitución, hoy San Antonio ${ }^{39}$, con elementos renacentistas, modernistas y regionalistas, o la, a estudio, Capilla del Beato Diego José de Cádiz.

Situada en el número 8 de la calle Bendición de Dios, donde nació el misionero, se inauguró el 24 de marzo de 1916 habiéndose dado la primera paletada en diciembre de 1914. Cabrera proyecta una capilla neogótica, de reducidas dimensiones, 17 metros de fondo, 7 de ancho y casi 10 de altura, de una sola nave abovedada y con nervaduras, presbiterio, coro alto y sacristía. Al exterior se proyectaron vidrieras de colores y una pequeña espadaña para acoger el cuerpo de campanas. Sus limitaciones y desnudez exteriores contrastan con el espíritu del interior, recogido y proporcionado, presidido por el estimable retablo, asimismo, gótico. Recientemente rehabilitada y de gran aceptación popular recibe distintos cultos así como a la Congregación del Santo Trisagio.

\footnotetext{
${ }^{36}$ www.mhcarquitectura.com/2010/06/resena-historica-del-edificio-cuc-cadiz (Consultado el 20-11-2014)

${ }^{37}$ CIRICI NARVAEZ, Juan R.: Juan de la Vega y la arquitectura..., op. cit., pp. 84-88.

${ }^{38}$ CIRICI NARVAEZ, Juan R. y RAMOS SANTANA, Alberto: Gran Teatro Falla, Cádiz, 1995.

${ }^{39}$ AHMC. SP., cajón 1, nº 65, 1910.
} 


\section{BREVE HISTORIA DE LAS OBRAS DE LA CATEDRAL NUEVA DE CÁDIZ.}

Cuentan que fue en un Cabildo celebrado el 3 de julio de 1716 cuando el maestro-escuela Juan de Zuloaga lanzó la idea de "que se premeditase si convendría edificar una nueva catedral" 40 . Aceptada la proposición el obispo Lorenzo Armengual de la Mota colocaba en mayo de 1722 la primera piedra de la fábrica que se encargó al insigne arquitecto Vicente Acero. Acero, de formación barroca, había trabajado en la construcción de la Capilla del Sagrario de la Catedral granadina y en la Catedral de Guadix. De allí, o simultáneamente, pasará a Cádiz donde elaborará los planos e iniciará las obras. Con un logrado dominio del movimiento, los volúmenes y la mixtificación de las líneas Acero adapta al gusto barroco el esquema de la planta renacentista de la Catedral de Granada de Diego de Siloé. Igualmente consigue imponer un ritmo único a todo el edificio, a base de utilizar una pilastra versátil y original que, mediante adosado de nuevas columnas y distorsión de su planta, se adapta a todas las posiciones, incluso a las difíciles de transición a la girola y capillas de ésta. El resultado no es una copia del modelo granadino sino que a partir de él se obtienen soluciones nuevas tanto en naves como en soportes, logrando introducir el juego borrominesco de curvas y movimiento ${ }^{41}$.

En el año 1731 pasa a dirigir las obras Gaspar Cayón quien construye las portadas, principal y laterales, culmina los pilares e inicia el cubrimiento de las bóvedas. Igualmente se le deben los motivos churriguerescos y rococó de los frisos y vanos. A Gaspar le sucede en el cargo su sobrino Torcuato Cayón, 1759, quién reforma la planta y el alzado introduciendo detalles del gusto clásico y francés. Sus planos de 1775 suponen una modificación sustancial del edificio: se reducen en un cuerpo las alturas de las cúpulas, central y del altar mayor, y de las torres. La cúpula central se proyecta de una sola hoja y linterna. Las torres, a pesar de su nueva proporción, conservan sensiblemente el perfil bulboso de las de Acero. Por primera vez se concibe el edificio como un cuerpo exento. En la fachada principal proyecta el acuerdo del frontón central con el muro mediante dos contrafuertes con volutas. Esta fachada, que es decorada con estatuas presenta un aspecto barroco con influencias francesas del momento.

A su muerte, en 1783, se encarga de las obras Miguel de Olivares. Formado en la escuela de Cayón lleva a cabo el cubrimiento de la nave central y el transepto y eleva la fachada principal y las torres se hasta la altura de la cornisa. Una disputa interna con el arquitecto José Prat lleva al Cabildo a solicitar el arbitrio de la

${ }^{40}$ MORENO CRIADO, Ricardo: Iglesias de Cádiz, op. cit., p. 42.

${ }^{41}$ ANTON SOLE, Pablo: La Catedral de Cádiz. Estudio Histórico y artístico de su arquitectura, Cádiz, 1975, p. 4. Ver tambien JIMÉNEZ MATA, Juan José: Vicente Acero y la Catedral Nueva de Cádiz, Cádiz, 2012. 
Academia madrileña de San Fernando. Con tal motivo llega de Madrid en 1787 Manuel Machuca que se encuentra con una obra barroca inconclusa y de mal aprecio dentro del nuevo estilo clasicista. Con las manos libres y dentro del estilo imperante el arquitecto madrileño diseña de nuevo las torres a manera de templetes coronados con jarrones de piedra. La cúpula queda proyectada de forma sencilla y austera pero conservando una airosa altura. No se había levantado el frontispicio y el cascarón de la fachada principal cuando la guerra con Inglaterra, en la que Cádiz se ve envuelta de forma directa, y, luego, la invasión y guerra con el francés, paralizaron definitivamente las obras. Faltaban por hacer la gran cúpula central, cerrar el trascoro, levantar las torres y construir la sacristía y antesacristía.

Un incendio producido la noche del 6 de enero de 1832 en una de las naves donde se almacenaba madera provocó la consiguiente indignación de la población gaditana. Las autoridades de la ciudad se vuelvan a reunir con el fin de dar una solución positiva a la fábrica encargándose su culminación al arquitecto y teniente coronel Juan Daura. En el tratamiento de la cúpula y por razones de presupuesto Daura rebajó la altura del tambor y de la elipse, suprimiendo la linterna y ofreciendo un exterior sin cuerpo de luces, construido de ladrillo y losetas cerámicas. El interior, por el contrario, luce un mayor interés, decorado con casetones de yeso propios de un neoclasicismo tardío impregnado, ya, de romanticismo. El resultado, poco airoso, -hoy más reivindicado- fue motivo de las críticas de la época. Después proyectará la sacristía y la antesacristía donde sí mostrará su real talento y valía como arquitecto y artista. Trabajaba precisamente en la construcción de las mismas cuando le sorprendió la muerte en 1844. Faltaban por hacer el Sagrario, las torres, la Sala Capitular y otras dependencias del capítulo. Además, el interior estaba deficientemente acondicionado.

A la muerte del obispo Domingo de Silos Moreno, marzo de 1853, su sucesor Juan José Arbolí y Acaso proclama continuar la obra iniciando un rosario ininterrumpido de intervenciones en donde el arquitecto diocesano -y de la provinciaJuan de la Vega y Correa tendrá un papel protagonista, paralelo a su evolución formal y que culmina en los planos para la construcción del Sagrario y Dependencias Capitulares de la catedral nueva gaditana.

Por orden cronológico en el año 1846 levanta la torre del lado este, en un intento de dar por acabada la fachada principal, no rematando hasta 1862 la del lado oeste. Para su construcción De la Vega utilizará, de forma literal, los planos y diseños que confeccionara años antes el arquitecto neoclásico Manuel Machuca $^{42}$, alcanzando una altura final de 57 metros y 67 centímetros y un diámetro de 13 metros y 57 centímetros.

${ }^{42}$ ACC. PMyD. (Archivo Catedralicio de Cádiz. Planos, mapas y dibujos), carpeta 1, $\mathrm{n}^{\circ} 7$ y $2, \mathrm{n}^{\circ} 3$. Tanto el alzado del conjunto de las torres y fachada principal como el dibujo de los jarrones a ejecutar. 
Conseguida en el año 1856 una nueva sillería para el coro, la existente además de pequeña era de nulo valor artístico, se encarga a De la Vega, ayudado por el escultor gaditano Juan Rosado, su restauración y colocación. Procedente de extinguida Cartuja de Santa María de las Cuevas sevillana ${ }^{43}$, donde quedaron otros dos trozos, se completaba con otros tramos de menor valor, fechados en la segunda mitad delXVIII, siendo la silla del obispo así como los paneles colindantes de nuevo diseño y ejecución. El conjunto quedará situado a los pies de la iglesia, en la nave central, en forma de cuadrado abierto por su frente, llevando cada lado dos órdenes de asientos con la silla del prelado en el testero principal a la que se accede mediante una escalinata y quedaba flanqueada por dos puertas que comunican con el trascoro. Tallada en maderas de cedro y caoba se alternaba la disposición renacentista con la ornamentación barroca.

Terminado el coro, se hacía necesario cerrarlo con una reja cuyo pensamiento corresponderá, igualmente, a De la Vega constituyendo uno de sus trabajos de mayor calidad artística y por el que recibirá todo tipo de alabanzas ${ }^{44}$. Forjada en Sevilla en los talleres de fundición de Manuel Grosso ${ }^{45}$, consta de cinco cuerpos en altura y siete tramos en longitud, tres de ellos móviles, abriéndose en el centro la puerta principal, de hoja doble, y alcanzando en este punto su máxima altura, 8 metros. Al más puro estilo del Renacimiento, una rica decoración de grutescos y candelabros recorre los bajorrelieves de las pilastras que limitan los tramos, con friso calado rematado en una artística y elegante crestería.

Mayor alcance tendrá la construcción del Altar Mayor. Diseñado con anterioridad, 1789, por el arquitecto Manuel Machuca el proyecto será recogido por De la Vega incorporando ligeras modificaciones. Propone Machuca un gran tabernáculo exento tomando como modelo el que para la Capilla del Escorial había proyectado Juan de Herrera y ejecutado el escultor italiano Jacome Trezzo en 1580. Consideraba también el arquitecto que el original, de pequeño tamaño, 4 metros de altura aproximadamente, en la majestuosa monumentalidad del presbiterio escurialense no reclamaba para sí toda la atención que merecía su excepcional traza, perfecta ejecución y ricos materiales. Por ello, y copiando, literalmente, el proyecto herreriano, que el mismo cita en $\operatorname{los} \operatorname{planos}^{46}$, le otorga una mayor altura, 14

${ }^{43}$ Obra de Agustín Perea, ayudado por su hijo Miguel y por el ensamblador Jerónimo de Valencia entre 1697 y 1702.

${ }^{44}$ ROSETTY, José: Guía de Cádiz..., año 1874, p. 174, la califica de "obra de extraordinario mérito...".

${ }^{45}$ QUINTERO ATAURI, Pelayo: "La Catedral de Cádiz", Cádiz, 1912.

${ }^{46}$ En los planos de la planta y alzado, aunque firmados y fechados por Manuel Machuca a 23 de septiembre de 1879, puede leerse: "Alzado del Tabernáculo del Escorial, ideado por el célebre arquitecto de Felipe II Juan de Herrera" y "Planta del Tabernáculo del Escorial,...", Colección Particular. 
metros, reduciendo, eso sí, la variedad de los motivos escultóricos y la riqueza de los materiales.

Reducción, que, por su parte, De la Vega atempera; cambia la planta circular por una mixtilínea, mantiene el orden corintio pero colocando columnas dobles estriadas, en vez de las simples y lisas de Machuca, y dota al conjunto de policromía al disponer las basas y capiteles de las columnas sobredorados al fuego contrastando con el mármol blanco de los fustes. El templete se completa con una semiesfera peraltada sobre tambor en el que alternan los huecos circulares con los rectangulares, incorporando sobre la pronunciada cornisa del entablamento una serie de ocho estatuas de santos. La cúpula, que en origen se hallaba rematada por una clásica linterna renacentista, es sustituida por un basamento circular sobre el que un grupo de dos ángeles sostienen una cruz de bronce. Frente a las intenciones de Machuca, De la Vega hace una regresión a las fuentes originales renacentistas recuperando movimiento y colorido y, sobre todo, pronunciando en una mayor calidad y contraste de los materiales, mármol, jaspes y bronce sobredorado.

Ubicado en el presbiterio, frente al coro, se eleva 13 metros sobre una plataforma de 17,50 de diámetro y a la que se accede mediante un graderío de mármol rojo de cinco escalones en línea con los pilares en los que se apoya el arco toral del transepto. La primera piedra será colocada el 28 de septiembre de 1862, aprovechando la visita de la Reina Isabel II y familia a la ciudad ${ }^{47}$, prolongándose los trabajos, no sin polémica, hasta agosto de 1866.

Simultáneamente, De la Vega proyecta ${ }^{48}$ y lleva a cabo sendos púlpitos, 1863, uno a cada lado del Altar Mayor. Dentro de la sugestión clasicista los púlpitos arrancan de los pilares del arco toral del presbiterio, deslizándose serpenteante a través de un corredor abalaustrado que conecta la cátedra con la puerta de acceso. Tanto la balaustrada como la cátedra están talladas y sobredoradas destacando esta última, de trazado octogonal, ofreciendo en sus lados aveneradas hornacinas con esculturas de santos. Disposición y motivos decorativos evocan inequívocamente el Renacimiento.

Al margen de estos trabajos reseñados cabe señalar distintas intervenciones en la cripta $^{49}$, recorrido de las cubiertas y diseño de la caja e incorporación de un nuevo órgano ${ }^{50}$.

${ }^{47}$ PONGILIONI, Arístides e HIDALGO, Francisco de Paula: Crónica del Viaje de SS.MM. y AA.RR. a las provincias de Andalucía en 1862, Cádiz, 1863, p. 208 y ss.

${ }^{48}$ AABAC. OD., año 1861

${ }^{49}$ ROSETTY, José: Guía de Cádiz..., op. cit., p. 174.

${ }^{50}$ AABAC. OD., año 1860. 


\section{ANTEPROYECTO DE CAPILLA DE SAGRARIO Y DEPENDENCIAS CAPITULARES.}

Y llegamos al punto de confluencia del presente trabajo. Restaba aún por levantar el Sagrario de la Catedral así como la, casi, totalidad de las dependencias capitulares. Y en remediar esta falta estaban Cabildo, presidido por D. Vicente Calvo y Valero, y arquitecto diocesano, Juan de la Vega, cuando en 1872 presenta éste un ambicioso y, en cierta medida, original proyecto de Sagrario y Salas Capitulares de enfatizado estilo gótico, con abundancia de arcos apuntados y bóvedas de crucería, interior, ventanas geminadas y rosetones, gabletes, pináculos, cresterías, exterior, y demás elementos del estilo. No conocemos la justificación que de tan singular concepto pudiera hacer De la Vega, al no contar con memoria descriptiva, pero, incluso habiendo sido consultada la Real Academia de San Fernando, los planos no gustaron a los miembros del Capítulo por lo que quedaron $\sin$ ejecución ${ }^{51}$. Dicha inquietud se pone de manifiesto en las cartas cruzadas que el prelado Calvo y Valero, a nivel particular, mantiene con la Academia fernandina en la persona de su presidente Federico Madrazo y Kunzt ${ }^{52}$.

En la primera, fechada en Cádiz a $1^{\circ}$ de Febrero de 1872 y dirigida al "Director de la Real Academia de San Fernando”, el obispo Calvo lo hace a título personal, ignorando "si es licito a particulares elevar consultas o pedir dictámenes a la respetable Academia", no haciéndolo de oficio como correspondería a ambas instituciones, Obispado y Academia. Habla como "Obrero - sic- ... en esta Santa Iglesia Catedral,...esperando que se dignará manifestarme la opinión, siquiera sea confidencial, acerca del mismo de Vd. y a ser posible de la dicha Academia que preside". Llama, sin duda, la atención la circunstancia y el sigilo.

Hace historia el prelado, "Abierta al culto esta citada Sta. Iglesia el año 38 de este siglo, como seguramente sabrá Vd., aun quedaba que hacer en esta fecha cosas tan importantes como las torres, el altar mayor, el coro y el sagrario. Gracias al celo y desprendimiento de los Sres. Obispos, del Cabildo y de los fieles de esta generosa ciudad, las tres primeras están ya terminadas; y ahora se trata de que la cuarta se comience en breve. Tres años ha que se pensó lo mismo; y mi digno antecesor-J.J. Arbolí y Acaso-, hoy ya difunto, en el cargo expresado encomendó al Arquitecto de esta Provincia - a La sazón el mismo de la diócesis, el ya citado, Juan de la Vegala formación de los planos necesarios a el efecto, así de la planta, interior y fachada del templo, como de las oficinas capitulares y parroquiales. Queriendo este sin duda no solo reformar en el trazado del sagrario los defectos mayores o menores de que adolece la mencionada Catedral, sino emplear en él un estilo u orden más propio de

${ }^{51}$ ANTÓN SOLÉ, Pablo: Catálogo de planos, mapas y dibujos del Archivo Catedralicio de Cádiz, Cádiz, p. 27.

52 Ibídem. Citadas por Antón Solé no se hace referencia alguna a sus contenidos u orientaciones. ACC, legajo 2, serie II, sección $2^{\mathrm{a}}, 1872$. 
edificios eclesiásticos que el seguido en aquella, adoptó el ojival, compuesto de gótico y bizantino, dejando el greco-romano, que, como ciertamente sabrá Vd., es el de esta mencionada Sta. Iglesia", y presenta sus dudas, pues, dice, "Ya trazados los planos, hay quien cree que, previa la aprobación de quien tenga derecho de otorgarla..., deben desde luego ejecutarse por ser de orden más bello y adecuado para templo Católico que el de la Catedral. Otros por el contrario juzgan que no obstante esa mayor belleza y congruencia, deben formarse otros del mismo estilo que esta, para no quebrantar, siquiera fuese con ventaja, la unidad del edificio, toda vez que el sagrario tiene puerta interior a la expresada Sta. Iglesia, por ser su capilla primera y principal, y la fachada de aquel es de continuación como complemento de la de esta. Profano en la materia, someto en al criterio de Vd. estas dos opiniones, rogándole de nuevo que, si fuere dado con consejo y acuerdo de la ilustrada Academia de su digna dirección, se sirva manifestarme cual sea de ellas la más acertada y susceptible por lo mismo de seguirse." Reiterándose en la licencia el Obispo gaditano se despide agradecido.

Apenas una semana después, el 9 de Febrero de 1872, se recibe respuesta de Madrid firmada por el director de la Academia Federico de Madrazo. Primero accede gustoso a la solicitud, pues la institución, afirma, "Aunque... no tiene la obligación de consultar si no al Gobierno; y en los asuntos privados cuando él se lo manda, nunca deja de responder a una pregunta confidencial, inspirada por el deseo del acierto" y, tras haber oído a los Académicos Arquitectos ${ }^{53}$, con cuyas apreciaciones coincide, informa "...que no es fácil sin ver planos, ni saber las combinaciones artísticas que en estudio serio puede haber inspirado a su autor, aceptar ni desechar cosa alguna, mucho más cuando de la consulta de V. no se desprende con claridad que es lo que se va a hacer, si la Capilla-Sagrario, si la portada de ella, si un Sagrario-Tabernáculo para exponer al Señor". No obstante hace una cierta apreciación "De todos modos el estilo ojival, tan bello y adecuado en los templos de aquel carácter, es tan diferente, casi antitético del estilo de esa Catedral, que por bueno que fuese lo que se proyectase, siempre se despegaría del templo grecoromano", implicándose, estilísticamente, de alguna manera, "No sería tan chocante la diferencia, si al menos el proyecto se hiciese en el estilo plateresco florido, que no dista tanto del greco-romano como el ojival, y que se presta a hacer una cosa muy bella si cae en buenas manos". Finalmente, solicita "que, en la misma forma confidencial, nos enviase $V$. los planos que hayan hecho; y viéndolos podríamos concretar más nuestro parecer, y anticiparle el criterio con arreglo al cual juzgaremos el proyecto definitivo, cuando se envíe, como debe hacerse y está mandado, al examen de la Academia por conducto del Sr. Obispo y del Ministerio de Gracia y Justicia o del de Fomento...".

${ }^{53}$ Componían la Comisión en ese momento Juan B. Peyronnet, presidente, Lucio del Valle, José Eugenio de la Cámara, Antonio Ruiz de Salces, Francisco Jareño, Francisco Cubas, Antonio Cachavera y José Amador de los Ríos, miembros. 
Ruego que no se hace esperar y el $1^{\circ}$ de Marzo una nueva misiva del Obispo agradece las molestias y remite "fotografías de los planos necesarios al efecto, así de la Catedral nueva como del Sagrario de la misma que se proyecta edificar en esta Ciudad... con el fin de que ésta adoptase tal resolución con perfecto conocimiento de causa".

En la misma se especifican los planos, "que representan: el $1^{\circ}$ y $2^{\circ}$ la fachada $y$ una sección longitudinal de aquella, y los demás, $3^{\circ}, 4^{\circ}, 5^{\circ}$ y $6^{\circ}$, respectivamente las fachadas principal y lateral y dos secciones longitudinal y transversal del Sagrario", reiterándose, en "el punto principal de mi dicha consulta, o sea, si en la construcción del Sagrario debe adoptarse otro estilo o el mismo de la Catedral mencionada".

Tales fotos son las que, depositadas en el Archivo Catedralicio gaditano fueron publicadas en el ya citado Juan de la Vega y la arquitectura gaditana del Siglo $X I X$, en 1992. Sobre las mismas escribía, "A falta de los originales se conserva una pequeña colección de seis fotos ${ }^{54}$, fechadas en el año 1872, que representan, junto a una sección longitudinal de la Catedral y un alzado de la fachada principal de la misma, el "Anteproyecto de Capilla de Sagrario y dependencias capitulares". A la vista de las fotos los nuevos diseños, para una Catedral de concepción barroca y apariencia neoclásica, no dejan de ser chocantes y extraños". El tamaño aproximado de las placas es de 14 por 17 centímetros y el trazado en blanco y negro.

La primera fotografía donde no sólo la leyenda se hace ilegible, pues apenas se adivinan las líneas, es un alzado de la facha principal completa, cúpula y torres, señalándose la planta del mismo. Es copia del proyecto de fachada que anteriormente había ideado Machuca y cuyo original de 1789 también se encuentra en el Archivo Catedralicio. Al igual que en el caso anterior su inclusión está relacionada con el exterior de la misma, fachada principal, cúpula y torres, en la idea de dar una imagen formal del conjunto. En continuidad con la misma se levantarían el nuevo Sagrario y dependencias capitulares.

La segunda, corresponde a una sección longitudinal de la Catedral Nueva. La leyenda, como en casi todas las demás de la colección, resulta ilegible. El motivo de su inclusión podría estar relacionado con la necesidad de acoplamiento de la Catedral con los nuevos edificios. Se trata, igualmente, de un original anterior, posiblemente, también de Machuca y referente a las obras de remozado de bóvedas y techos y aprovechada para la ocasión. Antón Solé adjudica sendos planos a De la Vega y 1872. Cosa que, en ningún caso, se ajusta a la realidad. Distinto es el caso de las siguientes reproducciones.

La tercera lámina se rotula "Anteproyecto de Capilla del Sagrario y dependencias capitulares. Fachada principal". Plenamente goticista, el sentido vertical domina al horizontal. Se observa un pórtico retranqueado hacia afuera, bajo un arco ojival que se enmarca en un adornado gablete. Jambas y arquivoltas completan el hueco. Sobre el pórtico, en un segundo cuerpo, se abre un gran ventanal

\footnotetext{
${ }^{54}$ Sección Planos, Mapas y Dibujos. Carpeta 3, $\mathrm{n}^{\circ} 1,1$ bis, 2, 3, 4 y 5.
} 
geminado y acabado en celosía gótica en su parte superior. Un nuevo triángulo, que supera en altura al tejado a dos aguas de la cubierta, culmina la fachada. Rosetones y pináculos se convierten en los motivos ornamentales más repetidos. Dicha fachada darías continuidad a la ya existente y principal a la plaza.

En la cuarta foto, rotulada "Anteproyecto de Capilla del Sagrario y dependencias capitulares. Fachada lateral", se nos presenta un nuevo pórtico, bajo arco ojival, que se sitúa en el extremo del brazo del crucero y sobre el que se abre un enorme rosetón en un segundo cuerpo. Estribos de carácter románico se reparten ordenadamente a lo largo del lateral del muro y entre los mismos, nuevos rosetones dan paso libre a la luz. Las dependencias capitulares, adosadas al Sagrario, ofrecen al exterior amplios y regulares ventanales. De mejor visualidad que las demás se distinguen perfectamente la forma de cruz latina de la capilla y sus distintas partes, cabecera, crucero, transepto y pies. En este caso, la fachada se proyectaría en la calle lateral, hoy Vicente Acero.

El cartón número cinco, en pésimo estado de conservación y visibilidad, apenas deja entrever la sección longitudinal del nuevo edificio. Su leyenda, "Anteproyecto de Capilla de Sagrario y dependencias capitulares. Sección longitudinal". La nave central, con bóveda de ojiva y tejado a dos aguas, se sostiene sobre altísimos pilares de haces de columnillas y baquetones que se abren en distintas direcciones al llegar al techo. Desde los pies de la nave principal hasta el ábside de la cabecera se suceden cuatro tramos, dos, el transepto, de mayor amplitud, y uno.

La lámina número seis, en aceptable estado de visión, reza "Anteproyecto de $\mathrm{Ca}$ pilla del Sagrario y dependencias capitulares. Sección transversal". Se observan las tres naves, la central doble de ancha que las laterales; las bóvedas apuntadas con nervaduras; los rosetones y ventanas, geminadas y de ojivas; los pilares con baquetones, etc. Junto a la sección interior del Sagrario se observa también la fachada principal del edificio capitular. Sobre una pequeña escalinata se abre un sobrio pórtico enmarcado en un ordenado alzado de dos plantas y tres hileras de vanos. El edificio apunta a los palacios góticos del final del Medievo. Otra dependencia lateral, cupulada y con una pila bautismal en el centro, estaría destinada a baptisterio de la Catedral.

Pero cual no sería mi sorpresa cuando visitando una casa gaditana veo enmarcada en la pared la serie de planos y alzados originales del Anteproyecto de Capilla del Sagrario y dependencias capitulares ${ }^{55}$, los cuatro últimos examinados y conservados en las pequeñas y quebrantadas fotografías. Sin firma ni fecha a la vista, lo que podría poner en entredicho autoría y data, pero en perfecto estado de conservación me fue permitida su reproducción que ahora expongo a la consideración general. De unas dimensiones aproximadas al 0,70x1 metro, a la precisión de la plumilla hay que unir la rica gama de ocres y carmines otorgando a los cuadros una bella y sugestiva vistosidad.

${ }^{55}$ Valga la cita como "Colección particular". 
Completando la serie, y para su lógica y mejor explicación, al grupo de los cuatro reseñados hay que añadir un quinto y que por considerarse no necesario para el juicio académico no fue fotografiado en 1872. Es el plano de situación, no solo esclarecedor de la ubicación y disposición de las distintas dependencias sino también del entorno, callejero y su caserío. Legible la leyenda, como en los demás planos, especifica "Plano Geométrico de la zona de población en que está situada la Santa Iglesia Catedral de Cádiz y en el cual se representa con tinta roja el emplazamiento del proyecto de Capilla del Sagrario y dependencias Capitulares", manifestando no solo el emplazamiento y proyección del nuevo proyecto, " $C C$ ", sino también los anteriores de Vicente Acero, "AA... cuyos alzados son desconocidos" y de Manuel Machuca, “ $B B$ ”.

Puesto a la luz el hallazgo restaban aún varias dudas por resolver, la primera y principal, la respuesta, oficial o no, de la Academia fernandina, y la segunda, dependiente, posiblemente, de la anterior, porqué no llegó a ejecutarse nunca el proyecto. En el Archivo Catedralicio gaditano no hemos encontrado noticia nueva alguna al margen de las ya citadas cartas y colección fotográfica. Para el caso fueron revisadas tanto la Sección de Planos, Mapas y Dibujos como los Libros de Actas Capitulares y las distintas Secciones de Legajos correspondientes a la segunda mitad del siglo XIX.

Espulgada, con el mayor de los celos, y respeto, la Academia madrileña tampoco hallamos mención ni documento que sugiera, al menos, la existencia tanto de las tribulaciones del prelado como del proyecto. Así pues se hizo examen de los Libros de Actas de la Sesiones particulares, ordinarias, generales, extraordinarias, públicas y solemnes (1752-1984), años 1870 y 1875, los Libros de Actas de las Sesiones Juntas Ordinarias de la Sección de Arquitectura, con los correspondientes legajos de Informes, los Libros de Actas de la Sesiones celebradas por la Comisión Central de Monumentos Históricos y Artísticos (1844-1983), con 95 títulos asociados pero donde faltan, precisamente, los años 1871 y 1872, otros tantos legajos de distinta índole, Comisión Central de Monumentos, Secretaría General, Comisiones Especiales, etc. así como los distintos Boletines de la Real Academia de Bellas Artes San Fernando, números 102-105, convenientemente encuadernados y donde figuran la serie de Proyectos, planos y dibujos... presentes en la institución.

A resulta de todo ello, y a manera de epílogo, destacamos la existencia real del proyecto, de admirable presencia, por cierto, y lo controvertido del mismo, al menos en el orden formal; el carácter confidencial de la consulta, silenciada por todas las partes y sin referencia oficial alguna; la -posible- reprobación académica; y, consecuentemente, su definitivo rechazo por el Cabildo catedralicio gaditano.

Fecha de recepción: 30 de septiembre de 2014

Fecha de aceptación: 28 de noviembre de 2014 

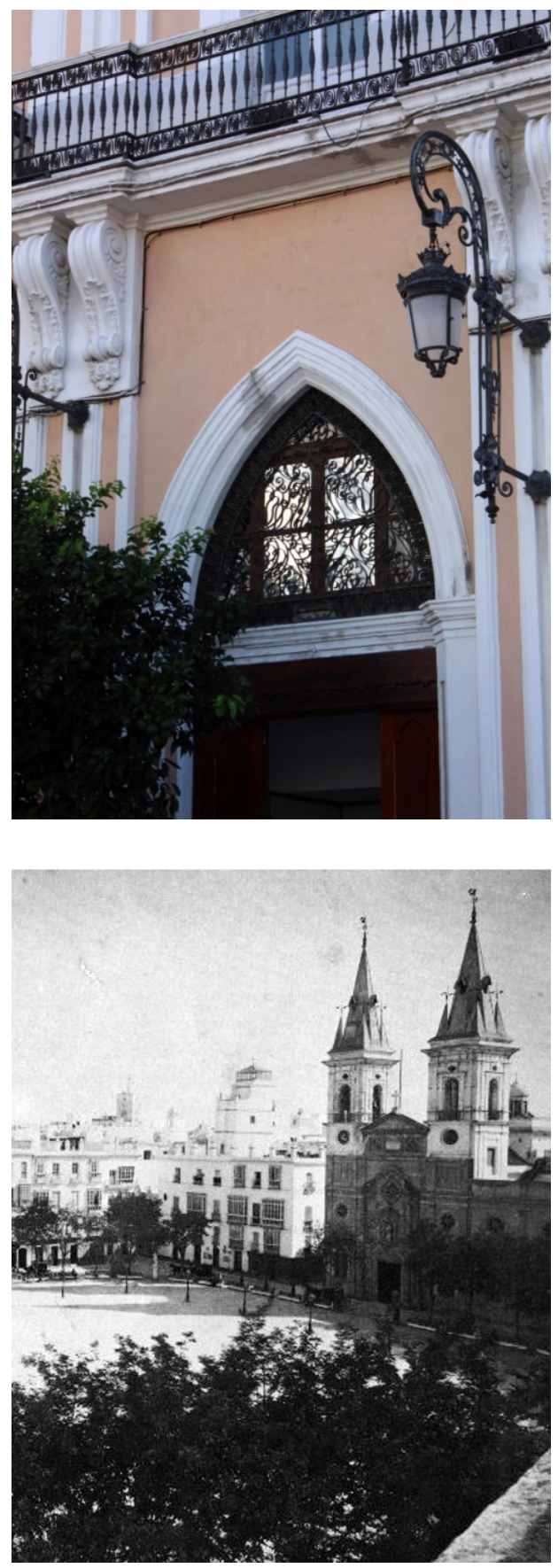

Figura 1. Detalle finca Plaza de San Antonio, 6, Cádiz. D. Filguera, 1857.

Figura 2. Parroquia de San Antonio, Cádiz. F. Ortiz Vierna, 1871. 


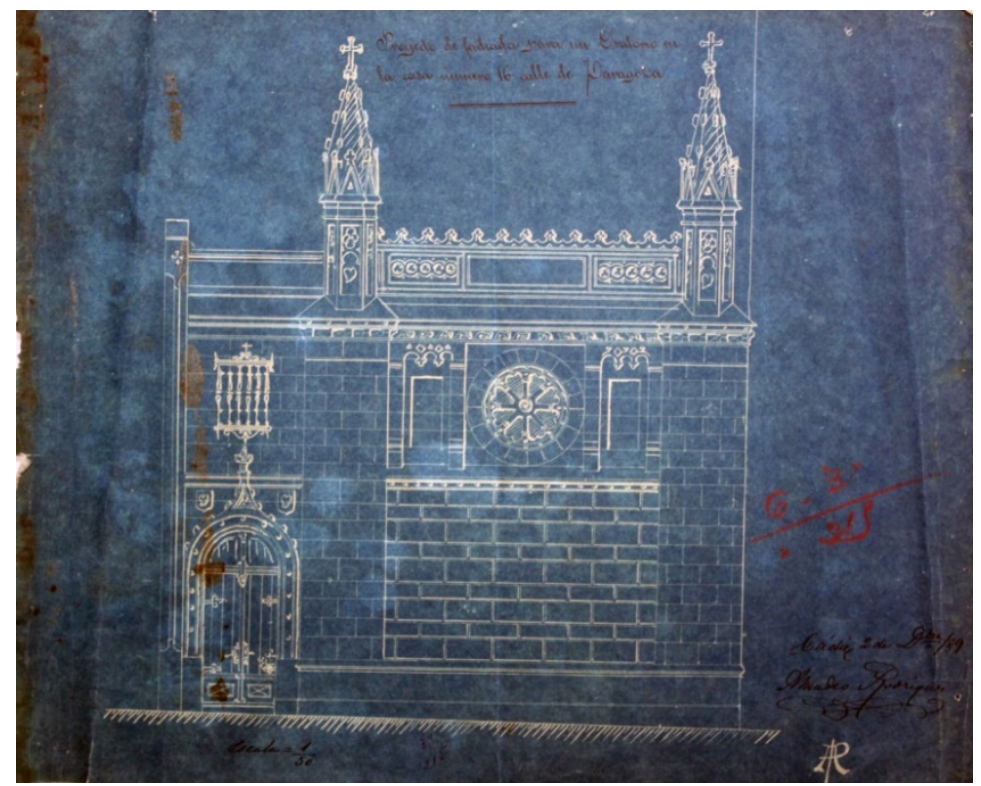

Figura 3. Capilla de las Reparadoras, Cádiz. A. Rodríguez, 1889.

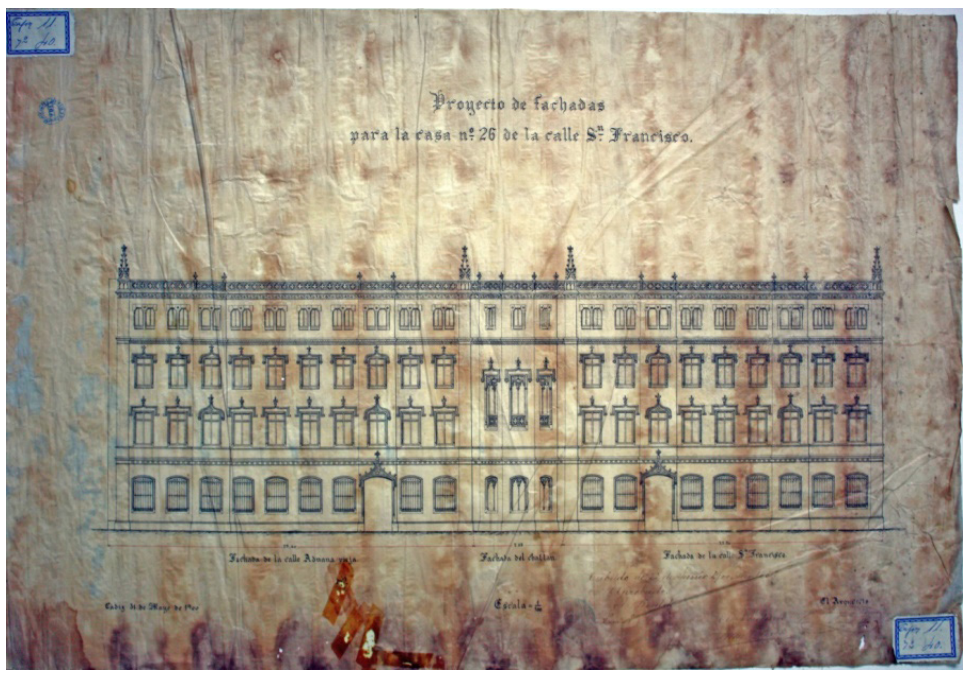

Figura 4. Colegio de San José -Esclavas S. C.-, San Francisco, 26. B. Romero Fernández, 1900. 


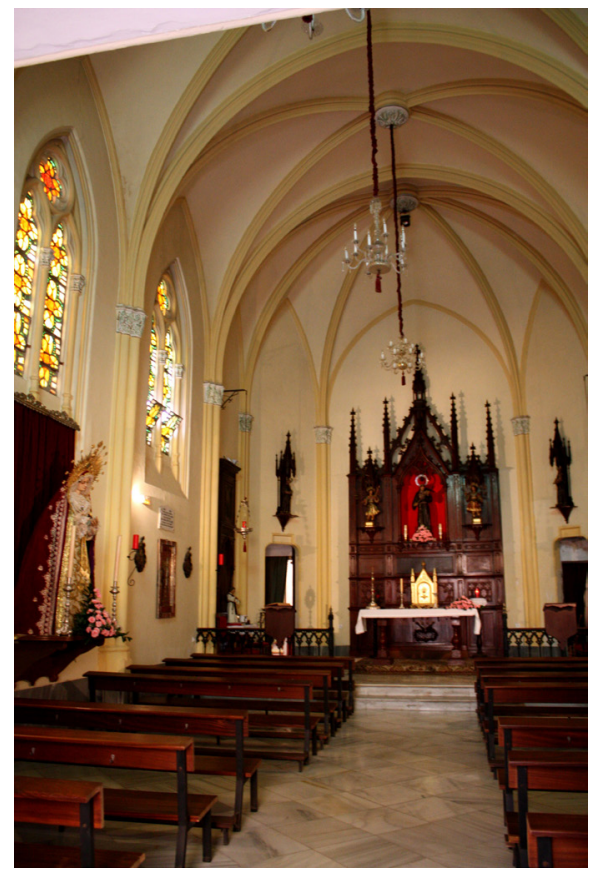

Figura 5. Interior Iglesia Beato José Diego de Cádiz, Cádiz. J. Cabrera Latorre, 1916.

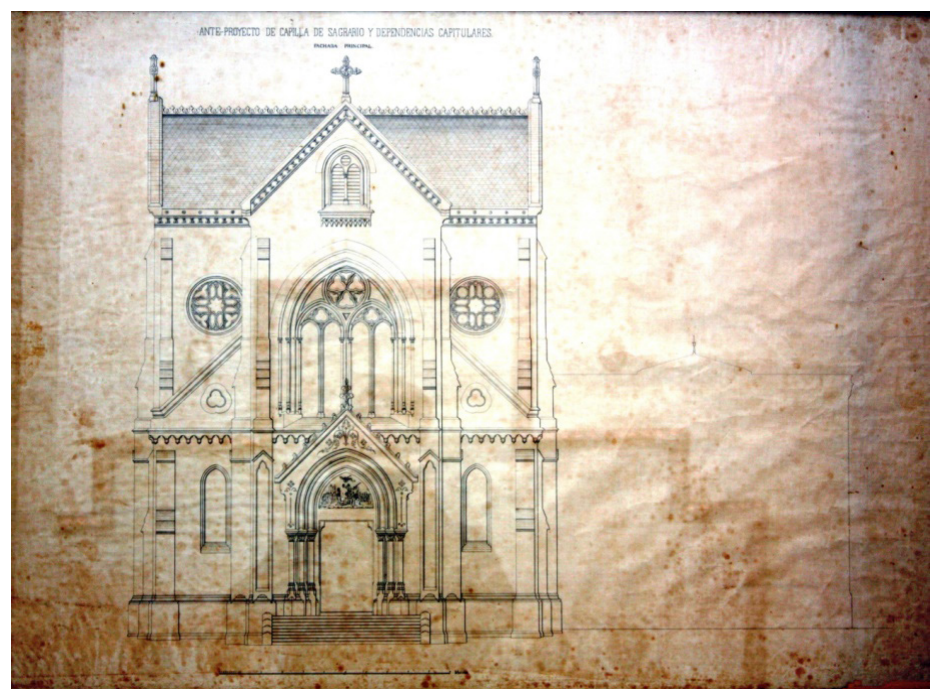

Figura 6. Anteproyecto de Capilla del Sagrario y dependencias capitulares. Fachada principal. 


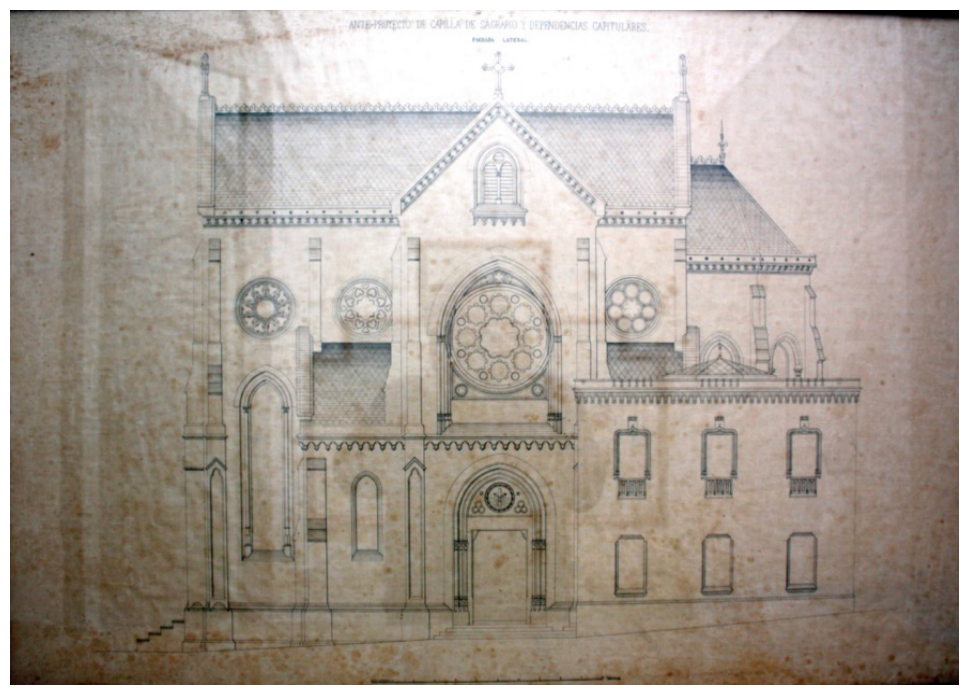

Figura 7. Anteproyecto de Capilla del Sagrario y dependencias capitulares. Fachada lateral.

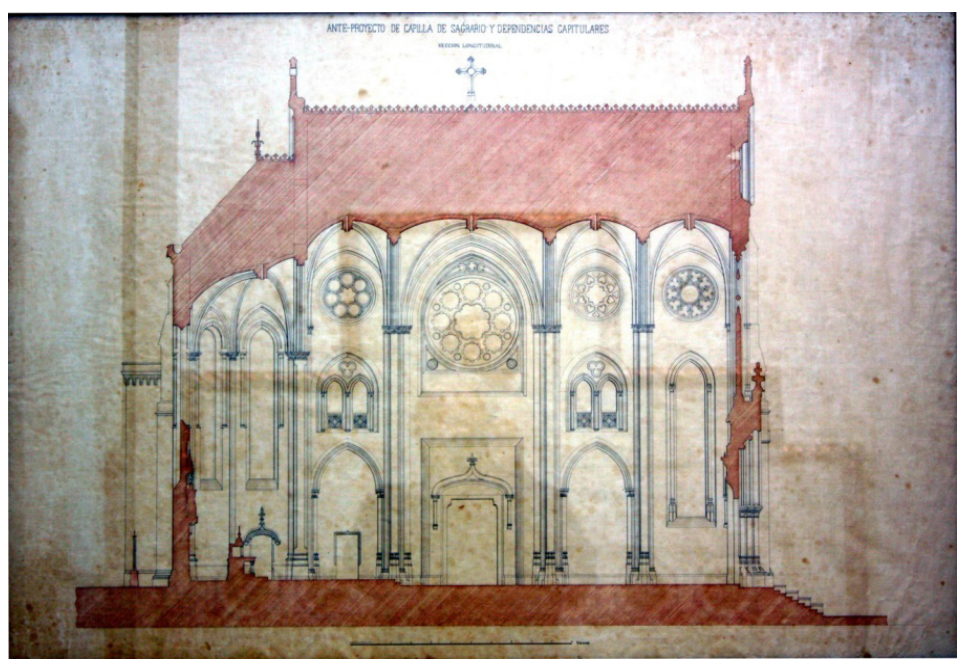

Figura 8. Anteproyecto de Capilla del Sagrario y dependencias capitulares. Sección longitudinal. 


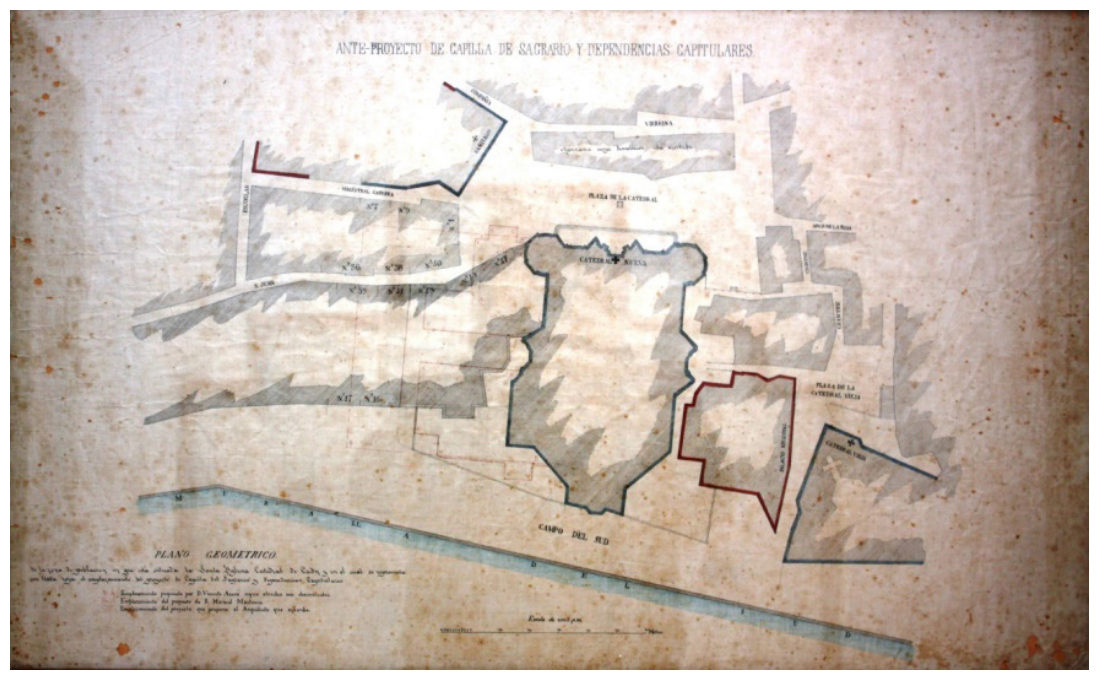

Figura 9. Anteproyecto de Capilla del Sagrario y dependencias capitulares. Plano geométrico.

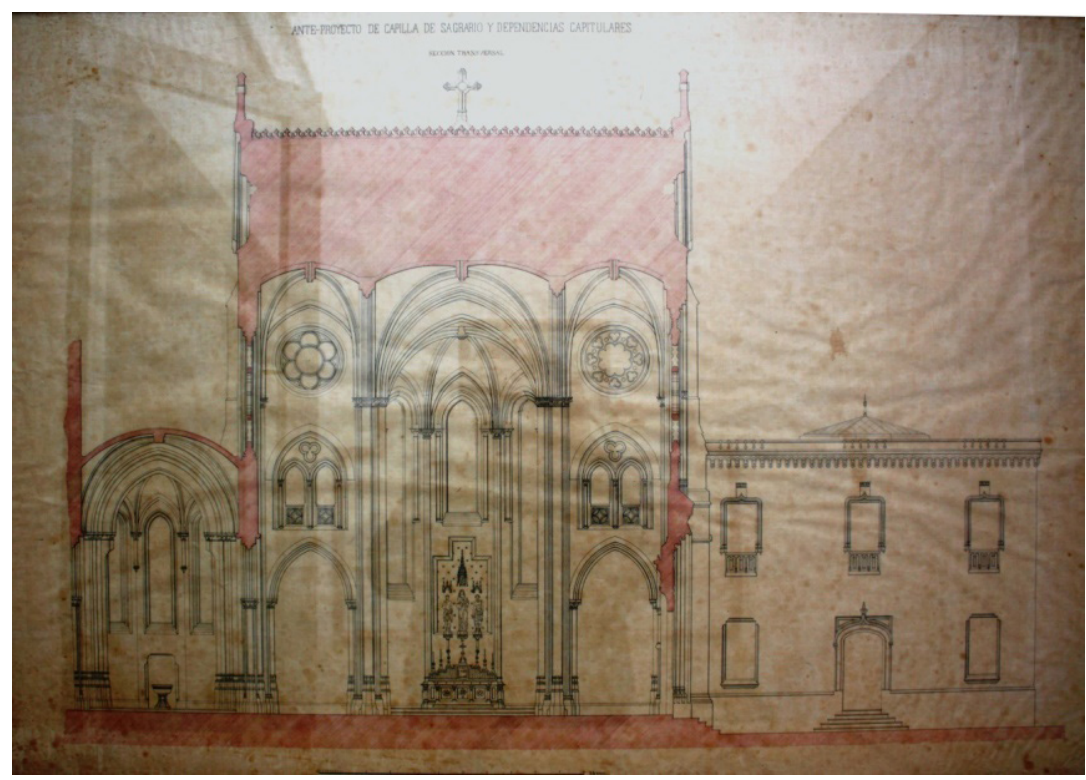

Figura 10. Anteproyecto de Capilla del Sagrario y dependencias capitulares. Sección transversal. 